\title{
New Polymer Networks for PDLC Films Application
}

\author{
Ana Isabel Mouquinho, Krasimira Petrova, \\ Maria Teresa Barros and João Sotomayor
}

Additional information is available at the end of the chapter

http://dx.doi.org/10.5772/48203

\section{Introduction}

\subsection{Polymer Dispersed Liquid Crystals}

Polymer dispersed liquid crystal (PDLC) films are a mixed phase of nematic liquid crystals (LC) commonly dispersed as inclusions in a solid polymer ${ }^{1}$. They have remarkable electrooptical behaviour since they can be switched from an opaque to a transparent state simply by application of an electric field ${ }^{2}$.

PDLCs have been prepared by two general methods: one in which the system remains heterogeneous during the process, and another in which the system becomes heterogeneous. The first case includes the solvent induced phase separation (SIPS): the LC is mechanically dispersed in solution of a polymer. After evaporation of the solvent, the composite structure obtained is stabilised because of the polymer morphology, but is poorly controlled due to a coalescence of droplets during the preparation process. The second case is called thermally induced phase separation (TIPS) or polymerisation induced phase separation (PIPS) ${ }^{1}$.

The main advantage of preparation by the PIPS method is the possibility to obtain a composite directly between glass plates coated with conductive indium tin oxide (ITO) film without additional laminating procedures. Thus, the PDLC film is produced in one technological step, in which the phase separation of the initially homogeneous mixture and the polymerisation occur simultaneously. The PIPS process was particularly suitable for our purpose because it is quite simple and allows for high degree of control over the final properties of the PDLC films. ${ }^{3}$

In this work the PIPS method was performed by thermal or photochemical polymerisation of a homogeneous mixture of polymerisable monomers, initiator and liquid crystal. These 
types polymerisations occur by the mechanism of free radical polymerisation, as explained bellow.

\subsection{Free radical polymerisation}

Free radical polymerisation has been widely practiced method for chain polymerisation and has been used in this work. This type of polymerisation can be described in three steps: initiation, propagation and termination. It is initiated by radicals - chemical species characterised by unpaired electrons which subsequently initiate polymerisations. Radicals can be formed by monomers themselves without added initiators (self-polymerisation) but normally by the action of initiators which were added deliberately. The decomposition of initiators in radicals can be achieved electrochemically, thermally or photochemically. Depending on the polymerisation conditions, the same monomer can originate polymers that differ in configuration, molecular mass and therefore in properties. In this work more attention was given to the thermal and photochemical polymerisation.

In thermal polymerisation the $\mathrm{N}, \mathrm{N}$-azobisisobutyronitrile (AIBN) is one of the most common initiator which fragments mainly into isobutyronitrile radicals (figure 1).<smiles></smiles>

Figure 1. Reaction scheme for the thermal decomposition of $\mathrm{N}, \mathrm{N}$-azobisisobutyronitrile (AIBN) in two isobutyronitrile radicals.

Thermal initiator decomposition normally depends on temperature, but also on the solvent used and its solubility. AIBN decomposition normally occurs to an appreciable extent at temperatures higher than $64^{\circ} \mathrm{C}$.

In photochemical polymerisation, light sensitive compounds are required as initiators. These compounds absorb light in the ultraviolet / visible wavelength range and undergo fragmentation leading to the formation of radicals ${ }^{4}$. An example is the photochemical decomposition of 2,2-dimethoxy-2-phenylacetophenone (DMPA) which is illustrated in figure 2. The main advantage of polymerisation with UV radiation is the possibility to achieve high polymerisation rates in a fraction of second ${ }^{5}$.

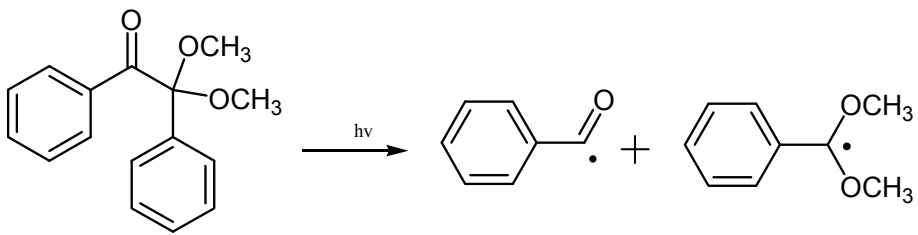

Figure 2. Reaction scheme for UV induced decomposition of 2,2-dimethoxy-2-phenylacetophenone (DMPA) into a benzoyl and an acetal radical fragments. 
However, for thermal and photochemical initiators, it is necessary to take into account that some of the radicals formed may recombine in secondary reactions to form compounds that cannot decompose further into radicals and therefore only some radicals are useful to initiate a chain reaction.

The initiation step includes radical production (described above for the AIBN and DMPA) and the attack of these radicals to the monomer molecules. The overall mechanism for free radical chain polymerisation can be described as:

Initiation:

i. Generation of free radicals (R·) by homolytic dissociation of the initiator (I).

$$
\mathrm{I} \stackrel{k_{d}}{\rightarrow} 2 \mathrm{R} \cdot
$$

( $k_{d}$ - rate constant for the dissociation of the initiator)

ii. Reaction between radicals $(\mathrm{R} \cdot)$ previously formed and monomer's double bond $\left(\mathrm{M}_{1}\right)$ producing new active species $\left(\mathrm{M}_{1} \cdot\right)$.

$$
\mathrm{R} \cdot+\mathrm{M}_{1} \stackrel{k_{1}}{\rightarrow} \mathrm{M}_{1} \bullet
$$

( $k_{1}$ - rate constant for the initiation step)

Propagation:

i. Chain extension by successive addition of monomer molecules (M) to the monomer radical unities $\left(\mathrm{Mn}^{*}\right)$ formed in the initiation step.

$$
\mathrm{M}_{\mathrm{n}} \cdot+\mathrm{M}_{\mathrm{m}} \cdot \stackrel{k_{t c}}{\rightarrow} \mathrm{M}_{\mathrm{n}+\mathrm{m}}
$$

( $k_{p}$ - rate constant for the propagation step)

Termination:

In last step, radicals combine or disproportionate to terminate the chain growth and form polymer molecules.

i. Combination (a simple interaction between two reactive species, $\mathrm{Mn}^{*}$ and $\mathrm{Mm}^{*}$ ).

$$
\mathrm{M}_{\mathrm{n}} \cdot+\mathrm{M}_{\mathrm{m}} \cdot \stackrel{k_{t c}}{\rightarrow} \mathrm{M}_{\mathrm{n}+\mathrm{m}}
$$

( $k_{t c}-$ rate constant for the termination step by combination)

ii. Disproportionation (when hydrogen atom is transferred from one chain to another).

$$
\mathrm{M}_{\mathrm{n}} \cdot+\mathrm{M}_{\mathrm{m}} \cdot \stackrel{k_{t d}}{\rightarrow} \mathrm{M}_{\mathrm{n}}+\mathrm{M}_{\mathrm{m}}
$$


( $k_{t d}$ - rate constant for the termination step by disproportionation)

\subsection{The nematic liquid crystal mixture E7}

The liquid crystal used in this work was thermotropic calamitic nematic, know as E7. It is a mixture composed by three different cyanobiphenyls and one cyanotriphenyl in different proportions. The molecular structures of the different components of the nematic liquid crystal E7 are shown in figure 3. The mass percentage and physical properties of E7 components are shown in table $1^{6,7}$.

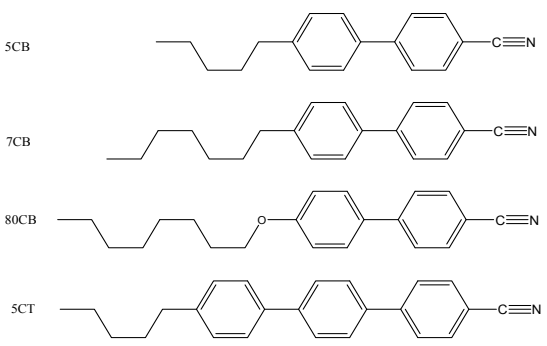

Figure 3. Molecular structures of the components of the nematic liquid crystal mixture E7.

E7 is widely used in polymer dispersed liquid crystals, and it was selected to be studied in this work, because it offers a wide range of operating temperatures in which it maintains anisotropic characteristics. The refractive indices of $\mathrm{E} 7$ at $\mathrm{T}=20^{\circ} \mathrm{C}$ are given as: no $=1.5183$ (ordinary refractive index) and ne $=1.7378$ (extraordinary refractive index) ${ }^{2}$. It exhibits a nematic to isotropic transition at nearly $\mathrm{T}_{\mathrm{Nl}}=58^{\circ} \mathrm{C}$. At room temperature it still exhibits a nematic phase and no other transitions between 58 and $-62^{\circ} \mathrm{C}$, where it shows a glass transition. Therefore, liquid crystalline properties are extended down to the glass transition 7 . These features are possibly due to the multicomponent nature of E76.

\begin{tabular}{c|cccc}
\hline Designation & \multirow{2}{*}{ Molecular formula } & IUPAC name & $\begin{array}{c}\text { Composition } \\
\mathbf{( w / w} / \mathbf{w}\end{array}$ & $\mathbf{T}_{\mathbf{N I}}\left({ }^{\circ} \mathbf{C}\right)$ \\
\hline $5 \mathbf{C B}$ & $\mathrm{C}_{18} \mathrm{H}_{19} \mathrm{~N}$ & 4-cyano-4'-pentyl-1,1'-biphenyl & $51 \%$ & 35.3 \\
$7 \mathrm{CB}$ & $\mathrm{C}_{20} \mathrm{H}_{23} \mathrm{~N}$ & 4-n-heptyl-4'cyanobiphenyl & $25 \%$ & 42.8 \\
$\mathbf{8 O C B}$ & $\mathrm{C}_{21} \mathrm{H}_{25} \mathrm{NO}$ & $4,4^{\prime}$-n-octyloxycyanobiphenyl & $16 \%$ & 80 \\
$5 \mathbf{C T}$ & $\mathrm{C}_{24} \mathrm{H}_{23} \mathrm{~N}$ & 4'n-pentyl-4-cyanotriphenyl & $8 \%$ & 240 \\
\hline
\end{tabular}

Table 1. Components and mass composition of the Merck E7 liquid crystal.

\subsection{Microstructure of the polymer matrix}

During polymerisation of what is initially a homogeneous solution of monomers and LC molecules, the polymeric components grow in molecular weight, and when the two components become sufficiently incompatible, there is a decrease of LC solubility which induces formation of separate phases. The polymer matrix acquires a particular morphology with liquid crystal dispersed in its clusters ${ }^{1}$. The polymerisation conditions ${ }^{8}$, the chemical 
nature of the liquid crystal ${ }^{9}$ and the polymerisable monomers ${ }^{10}$ determine the morphology of polymer matrix. Conventional PDLCs have two main morphologies: Swiss cheese or polymer ball types each one with different characteristics. The observation of the microstructure of the polymer matrix was carried out by scanning electron microscopy (SEM). The dark areas in the SEM microphotographs reveal the absence of the material, which would have corresponded to the original liquid crystal domains.

The Swiss cheese morphology type (figure 4A) is characterised by liquid crystal randomly dispersed in a polymer matrix, as microdroplets. The size and shape of the LC microdroplets are in strong dependence on the parameters of preparation and the type of polymeric matrix ${ }^{11,12}$.
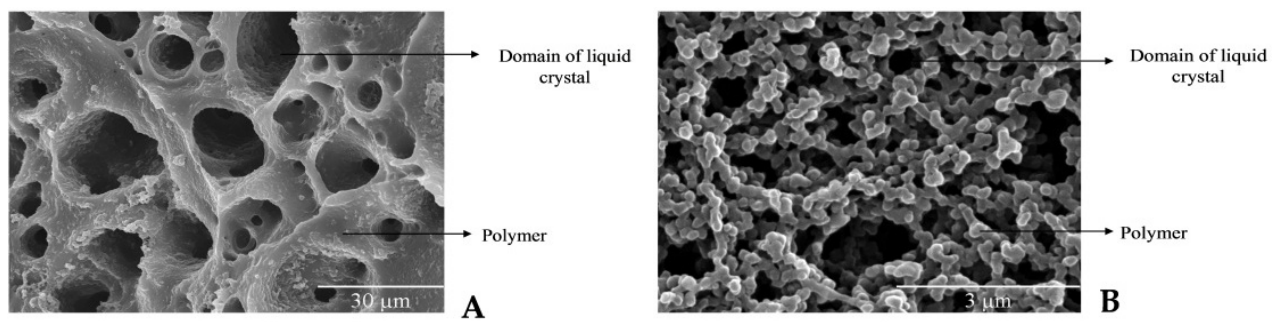

Figure 4. SEM micrograph for the microstructure of the polymer matrix with a A) Swiss cheese morphology type and B) polymer ball morphology type.

In PDLC morphologies with isolated LC microdroplets, two types of distribution of liquid crystal molecules are typically observed, as shown in figure 5.

The bipolar and radial configurations (figure 5) are related to droplet size and shape and depend on whether the liquid crystal prefers to align parallel or perpendicular to the polymer surface, respectively. Due to these different configurations, liquid crystal molecules would be randomly oriented within each droplet or from droplet to droplet, causing dispersion of the incident light.

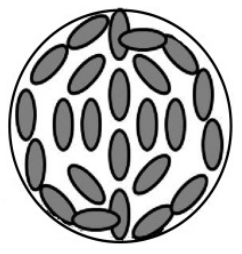

(a)

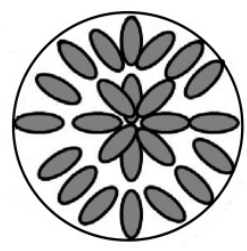

(b)

Figure 5. Schematic illustration of bipolar (A) and radial (B) director configurations of the liquid crystals inside spherical droplets.

In the polymer ball morphology type (figure $4 \mathrm{~B}$ ) the polymerisable monomers are phase separated from the continuous liquid crystals and form micro-sized polymer balls. These micro-sized polymer balls merge and form a large polymer network structure with diversely 
shaped voids in which LC exists. In this case, the LC is in a continuous phase and fills the irregular shaped voids of the polymer network, which are more or less interconnected ${ }^{12}$.

\subsection{PDLC films transmittance}

As mentioned before, PDLC devices can be switched electrically from an opaque scattering state to a highly transparent state when a film of liquid crystal-polymer mixture is sandwiched between two conductive glass slides and the electric field is applied. The polymer matrix material is optically isotropic so it has a single refractive index $\left(\mathrm{n}_{\mathrm{p}}\right)$. The liquid crystal within the micro-domains has an ordinary refractive index (no) and an extraordinary refractive index $\left(\mathrm{n}_{\mathrm{e}}\right)$ when light ray travel through the liquid crystal.

When no electric field is applied although the liquid crystal molecules would be oriented within each droplet, this orientation changes from droplet to droplet and light propagation normal to the film surface will experiment a range of refractive indices between (no) and (ne). Since the optical anisotropy of LC molecules used in PDLC is sufficiently large, the effective refractive index is not generally matched with the refractive index of the polymer $\left(\mathrm{n}_{\mathrm{p}}\right)$, light will be scattered and the PDLC is opaque (OFF state). To maximize off-state scattering, the birefringence $\left(\Delta n=n_{e}-n_{0}\right)$ should be as large as possible ${ }^{9}$. On the other hand, when an electric field with sufficient strength to overcome the interactions between polymer matrix and liquid crystal at interfaces of LC domains-polymer matrix, is applied across the film liquid crystal directors within each droplet become uniformly oriented parallel to the direction of the field. If refractive index of the liquid crystal matches the refractive index of the polymeric matrix $\left(\mathrm{n}_{\mathrm{p}}\right)$ the film become transparent $(\mathrm{ON} \text { state })^{13}$.

Normally, when the applied electric field is removed, the nematic directors return to their random distribution. The film begins to appear opaque again. A schematic representation of a functional PDLC film is shown in figure 6.

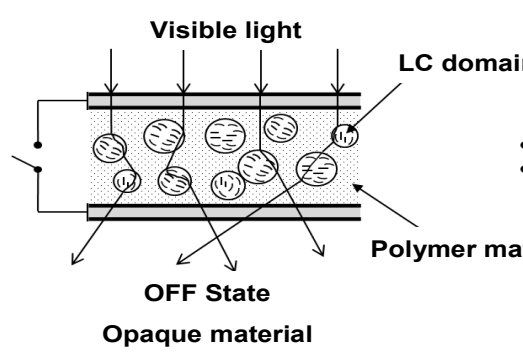

(a)

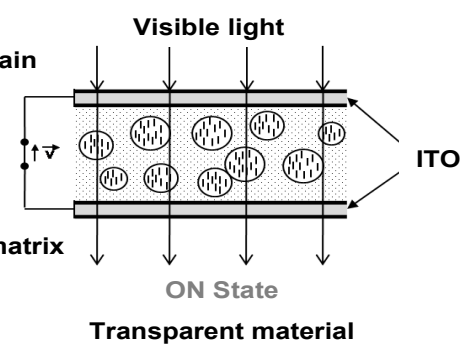

(b)

Figure 6. Schematic representation of the averaged molecular orientation of the liquid crystal within the microdroplets without (a) and with (b) an applied electric field.

\subsection{Electro-optical properties of PDLCs}

Three main types of electro-optical response can be observed (figure 7). The factors contributing to the different response are many and still poorly understood. Electro-optical 
response of PDLC is usually measured by ramping a PDLC up and down in voltage and comparing the optical response at each voltage ${ }^{1}$. The different types of change of transmittance of PDLC films as a function of the electric field are shown in figure 7.

One of the parameters used to evaluate the efficiency of electro optical response of PDLC is the electric field required to achieve $90 \%$ of the maximum transmittance and is designated as E90. Thus, the lower the value of E90, the more easily PDLC devices switch from the OFF state to ON state.

The most common electro-optical response reported in the literature for PDLC is when the increasing voltage curve is coincident to the decreasing voltage curve as shown in figure 7A. It was observed that when the electric field is removed liquid crystal molecules relax back, so that the long shaped molecules which were oriented in the same direction in each droplet return to their original random orientation.
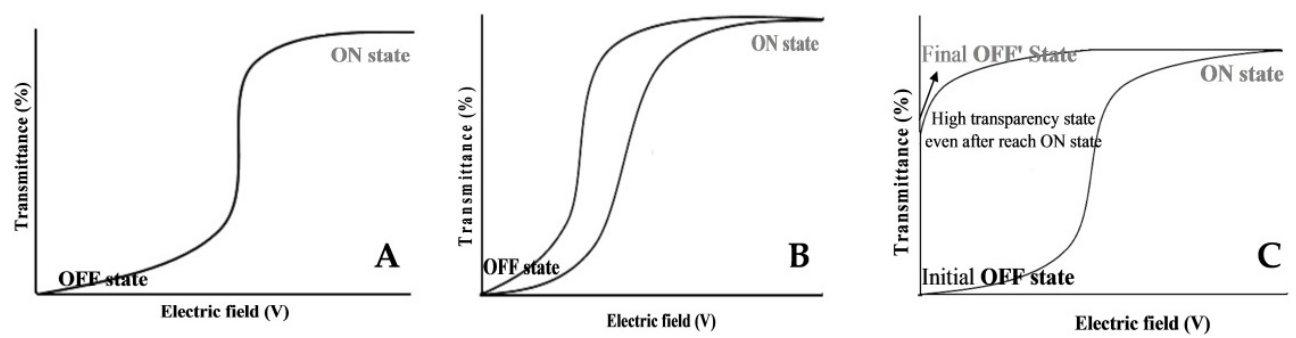

Figure 7. Example of electro-optical response of PDLC A) with no hysteresis, B) with hysteresis and C) with permanent memory effect.

When these curves are not coincident the PDLC shows electrical hysteresis. The transmission with increasing voltage is lower than the transmission when the electric field is decreased. This effect is illustrated on figure $7 \mathrm{~B}$ and can be defined as the difference between the increasing voltage curve and the decreasing voltage curve.

This difference is commonly attributed in literature to the fact that liquid crystal molecules have a tendency to remain with a certain degree of alignment even after removal of the electric field. The PDLC film is more transparent under decreasing field voltage than with increasing field, because liquid crystals remain with certain degree of alignment caused by the increasing field voltage. However, at the end of measured electro-optical response, the value of the transmittance for the initial opaque state is coincident with that of the final opaque state ${ }^{14}$.

In particular cases, not only the transmission with increasing voltage is lower than the transmission when the voltage is decreased but also a high transparency state is obtained for a long period of time at room temperature even after the applied voltage has been switched off, starting from an opaque state and later reaching a transparent state (figures 7C and 8) ${ }^{1}$.

In figures $7 \mathrm{C}$ and 8 , the initial OFF state corresponds to the transmittance of the initial opaque state (zero electric field), the $\mathrm{ON}$ state to the transmittance upon applying electric 
field and the final OFF' state is the transmittance after removal of the applied field. The PDLC film with this electro-optical response has a permanent memory effect and this still remains a poorly understood aspect of PDLC electro-optical behaviour.

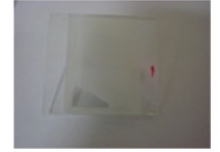

Initial OFF State

(a)

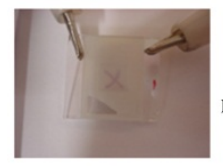

ON State

(b)

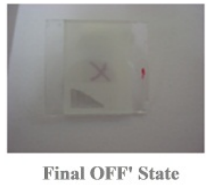

(c)

Figure 8. Images of PDLC devices with permanent memory effect: (a) initial OFF state, (b) upon applying electric field and (c) OFF state after removed electric field.

Various factors can influence the performance of a PDLC and therefore the permanent memory effect. However, the most frequently explanation mentioned in literature is related to the anchoring effect ${ }^{6,11}, 15,16$. This effect consists of the interaction between the liquid crystal molecules and polymer matrix at the interface of LC domains and polymer matrix. When an electric field is applied inducing the orientation of LC molecules, it opposes the anchoring effect. If this orientation remains even after the applied voltage has been switched off, the liquid crystal does not relax back completely but remains aligned with the electric field and a high transparency state is displayed without any more energy consumption. Therefore for this to happen there must be a weak force between LC molecules and the polymer surface.

The permanent memory effect is very revolutionary in the study of PDLCs because it allows a switch in transparency and the new state is kept without the need for energy to be spent. The only energy required is that needed to switch the PDLC from the OFF state to the ON state, therefore these devices become low power consumers and environmentally friendly.

\subsection{Parameters that influence the performance of PDLC films}

Despite the fact that PDLC films can be switched between a highly scattering opaque state and a clearly transparent state, these devices sometimes have disadvantages such as the high driving voltage (E90) and the insufficient maximum transmittance (TMAX) ${ }^{17}$. The electrooptical properties of PDLC films prepared by the polymerisation induced phase separation (PIPS) method depend on a numbers of factors such as the type of liquid crystal, molecular structure of polymerisable monomers and polymeric conditions. These factors could seriously affect the microstructure of the polymer matrix, the size and the shapes of the LC domains and molecular interactions between the LC molecules and the polymer matrix (anchoring effect) ${ }^{8,18-20}$. In general and in a simple way, in a nematic liquid crystal there is a relationship between the size and the shape of LC domains and the anchoring effect. When sizes decreased the anchoring effect increase. This effect is directly related with the voltage needed to align the liquid crystal molecules in the domain. Strong anchoring forces hinder the alignment of liquid crystal molecules. Therefore a high voltage is needed to align liquid 
crystal molecule along the electric field, and the reverse is valid for lower anchoring effects ${ }^{18}$. Therefore, an understanding of the relationships between preparation conditions and molecular structure of the monomers on electro-optical performance of PDLCs is crucial to control device properties.

\subsection{Polymerisation conditions}

The phase separation phenomenon between LC and polymeric matrix in PDLCs is a kinetic process where the transport parameters can play an important role in determining the domain size and amount of LC separated from the polymer matrix. The rate of polymerisation and also some physical parameters, such as the viscosity of the systems change the LC domain size. In general, the thermal polymerisation is slower (can take several hours), which combined with the effect of temperature that significantly decreases the viscosity of the medium may cause a promotion of the growth of LC domains by diffusion and coalescence. On the other hand, photochemical polymerisation produces a higher polymerisation rate. Smaller domain size can be achieved by higher viscosity of the systems and poor diffusion of free radicals of the polymerisable monomers during polymerisation and hence the reduced coalescence of LC domains. Therefore, small LC domains can be obtained ${ }^{8,20}$.

\subsection{Molecular structure of polymerisable monomers}

The electro-optical response of PDLC films is greatly influenced by molecular structure of the monomers to be incorporated as polymeric matrix ${ }^{10,19,20}$. In literature reports there is not a great variety of monomers used in research for applications for PDLC films, besides the most common commercial ones. To the best of our knowledge, published results of the synthesis of monomers to be incorporated as polymer matrix, were mainly dedicated to the preparation of monomers bearing a cyanobiphenyl group ${ }^{21,22}$. These monomers with a molecular structure similar to the E7 liquid crystal molecules, could lead to better miscibility and compatibility between the polymeric matrix and LCs during the preparation of PDLCs. This could lead to a uniform phase separation and control of the LC domains, which could enhance the performance of PDLCs. On the other hand, the low miscibility with the LC molecules can lead to a premature separation from the matrix. Therefore, one of the main objectives of this work was the design and synthesis of new photochemically and thermally polymerisable monomers, mimicking some structural elements of the E7 liquid crystal molecules. Besides the specific cyanobiphenyl groups, also aromatic systems in general with and without a linear chain spacer with five methylene units were synthesised. Thus, a number of aromatic mono- and dimethacrylates with and without spacer, as well as vinylic monomers, were synthesised under microwave irradiation. A linear chain spacer with five methylene units was introduced into some of the structures between the aromatic systems and the methacrylate group to mimic the structure of $5 \mathrm{CB}$, which is the liquid crystal component present with the highest percentage in E7. 


\section{Synthesis and characterisation}

As mentioned before, a number of photochemical and thermal polymerisable monomers, as well in some cases, their starting materials were prepared under microwave irradiation. The synthetic methods and the full characterisation of the compounds obtained have been described elsewhere ${ }^{23}$. All the compounds were synthesised using a microwave synthetic reactor under mild or solventless procedures. For some reactions, it was necessary to add a small amount of DMF (dimethylformamide) to obtain better homogenisation of the mixture. DMF was chosen because of its dipolar nature and the high ability to absorb microwave energy and convert it into heat, coupled with a comparatively high boiling point of $153^{\circ} \mathrm{C}^{24}$. The protocol employed consisted in placing equivalent amounts of the corresponding reagents in an open quartz tube and then subjecting the mixture to microwave irradiation at $200 \mathrm{~W}$. The reaction time was optimised by following the reactions by thin layer chromatography (TLC) every minute and stopped when no starting material remained. The authors have described ${ }^{23}$ the data of compounds characterisation by ${ }^{1} \mathrm{H}$ and ${ }^{13} \mathrm{C}$ NMR, FTIR spectroscopy, elemental analysis and melting points. Also, a comparison between the results described in the literature for the syntheses of the compounds under classical synthetic methods with the results obtained under microwave irradiation have been made. Part of the Gel Permeation Chromatography (GPC), Differential Scanning Calorimetry (DSC) and electro-optical studies presented here have been previously published ${ }^{26}$.

\subsection{List of synthesised monomers}

The molecular structures of all synthesised monomers are shown in figure 9. Some of the synthesised monomers have been already mentioned in the literature, but were lacking full characterisation, which was provided in ref. 23. This was the case for compounds: $1^{25}, 2^{27}$, $3^{25}, 4^{28}, 5^{29}, 6^{30}, 7^{29}, 9^{31}, 10,11^{32}, 13^{33}, 14^{34}, 15^{35}, 16^{36}, 25^{37}, 26^{38}$. To the best of our knowledge, the compounds $8,12,17,18,19,20,21,22,23$ and 24 had not been synthesised before.

\subsection{Selected monomers}

Among all the synthesised monomers, the monomers containing cyano and/or spacer chain group (figure 10) were studied further due to higher chemical structural compatibility with E7 liquid crystal molecules. The monomers (with cyano and/or with spacer chains groups) properties will be compared to the analogous monomers without cyano group and/or spacer chain and the results will be presented later on.

\subsection{Calorimetric characterisation}

In order to determine the transition temperatures and their associated enthalpies differential scanning calorimetry (DSC) was employed. Figures 11-14 present the DSC thermograms collected on heating and on cooling run of cycle I. This cycle corresponds to the first heating and cooling runs and the cycle II to the second heating and cooling runs. 


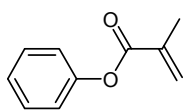

Phenyl methacrylate

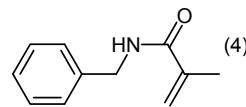

$\mathrm{N}$-benzylmethacrylamide
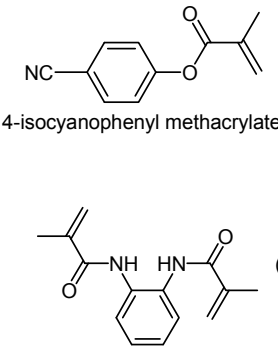

$\mathrm{N}, \mathrm{N}^{\prime}-(1,2-$ phenylene) bis(2methylacrylamide)
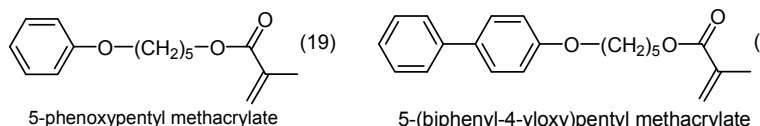

(20)<smiles>C=C(C)C(=O)Nc1ccc(Oc2ccc(NC(=O)C(=C)C)cc2)cc1</smiles>

Biphenyl-2,2'-diyl bis(2methylacrylate)

(11)

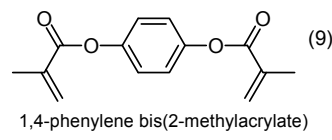

$\mathrm{N}, \mathrm{N}^{\prime}$-(4,4'-oxybis(4,1-phenylene))bis(2-methylacrylamide)

5-(biphenyl-4-yloxy)pentyl methacrylate

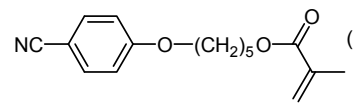

5-(4-cyanophenoxy)pentyl methacrylate

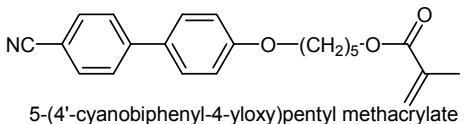

(22)

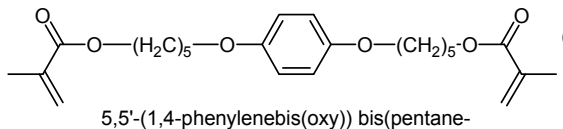
5,1-diyl) bis(2-methylacrylate)

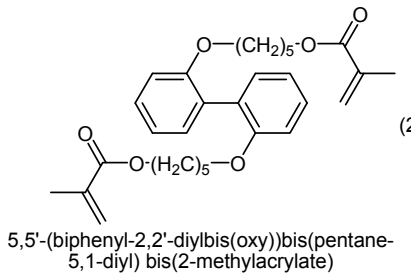

(24)

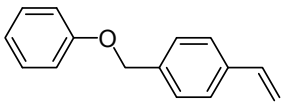

1-(phenoxymethyl)-4-vinylbenzene
(25)

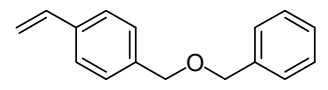

1-(benzyloxymethyl)-4-vinylbenzene

Figure 9. Molecular structures of synthesised monomers.

As mentioned before, the melting temperature $\left(\mathrm{T}_{\mathrm{m}}\right)$ was obtained at the peak of the melting endothermic transition, and in analogues way the crystallisation temperature either for cold( $\left.T_{c c}\right)$ or for melt- $\left(T_{c}\right)$ crystallisation was obtained at the peak of the respective exothermic transition peak. The glass transition temperature $\left(\mathrm{Tg}_{\mathrm{g}}\right)$ was taken at the inflection point of the specific heat capacity variation in the transition. The melting and crystallisation enthalpies 
$\left(\Delta \mathrm{H}_{\mathrm{m}}\right)$ and $\left(\Delta \mathrm{H}_{\mathrm{cr}}\right)$, respectively, were determined from the areas under the curve that represents the respective transitions. The information obtained on the temperatures and enthalpies is summarised in table 2.

Figure 11A presents the DSC thermogram collected on cycle I for liquid monomer 19. The heat flux presents a discontinuity characteristic of the glass transition at $T_{g}=-86.01^{\circ} \mathrm{C}$. At higher temperatures an exothermic peaks characteristic of cold crystallisation emerges at $40.19^{\circ} \mathrm{C}$ with an enthalpy of $-97.45 \mathrm{Jg}^{-1}$ followed by endothermic peak due to melting at $\mathrm{T}_{\mathrm{m}}=-$ $3.62^{\circ} \mathrm{C}$ with an enthalpy of $115.52 \mathrm{Jg}^{-1}$. During the first cooling rate no transitions were detected, so it is possible that the liquid remained in a supercooled state. During cycle II the same calorimetric behaviour as that obtained for cycle I was observed.<smiles>C=C(C)C(=O)Oc1ccc(-c2ccc(C#N)cc2)cc1</smiles><smiles>C=C(C)C(=O)OCCOc1ccc(-c2ccc(C#N)cc2)cc1</smiles>

5-(4'-cyanobiphenyl-4-yloxy)pentyl methacrylate<smiles>C=C(C)C(=O)Oc1ccc(C#N)cc1</smiles>

4-isocyanophenyl methacrylate<smiles>COc1ccc(C#N)cc1</smiles>

5-(biphenyl-4-yloxy)pentyl methacrylate

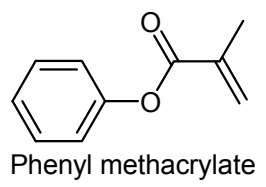

Biphenyl-4-yl methacrylate

Figure 10. Molecular structure of synthesised monomers with and without cyano and spacer chain group.

During cycle I for liquid monomer 1 (figure 11B) the thermogram showed endothermic peak at $18.86^{\circ} \mathrm{C}$ with an enthalpy of $108.97 \mathrm{Jg}^{-1}$ due to the melting of the crystalline form; on cooling rate no transitions were detected, thus the liquid could have remained in a supercooled state. However, during the cycle II the thermograms showed endothermic transitions assigned to a glass transitions at $\mathrm{T}_{\mathrm{g}}=-89.02^{\circ} \mathrm{C}$ and melting temperature at $\mathrm{T}_{\mathrm{m}}=18.86^{\circ} \mathrm{C}$ with an enthalpy of $107.67 \mathrm{Jg}^{-1}$. Cold crystallisation was also observed at $\mathrm{T}_{\mathrm{cc}}=-$ $55.13^{\circ} \mathrm{C}$ with an enthalpy of $-71.0 \mathrm{Jg}^{-1}$. These thermal transitions were very similar to those observed in the thermogram obtained for liquid monomer 19 (figure 11A). 

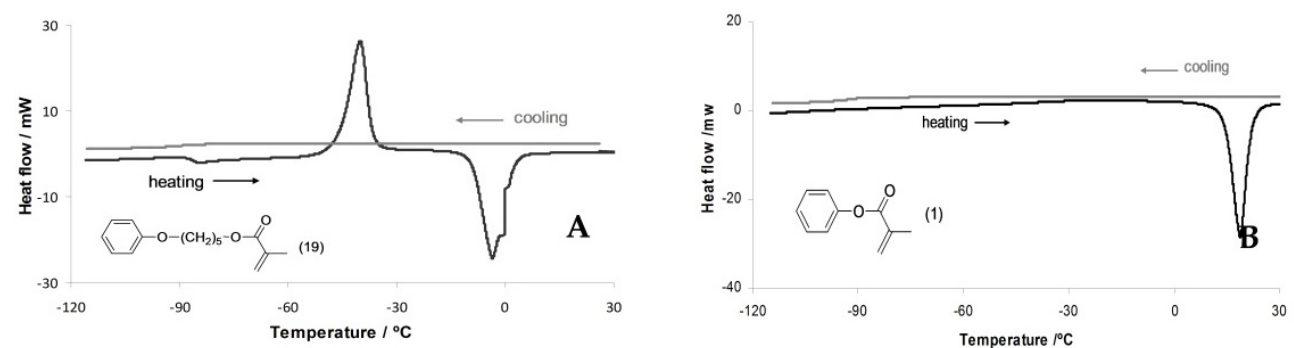

Figure 11. DSC measurement obtained for A) monomer 19 and B) monomer 1 during cycle $\mathrm{I}$ at $10^{\circ} \mathrm{C}$ $\min ^{-1}$.

The solid monomers, 7, 5, 22, 21 and 20 had different thermal behaviour compared with the liquid monomers (19 and 1) described above. The thermograms for monomers 7, 5, 22 and 21 in figures 12 and 13, showed reversible systems that on heating gave endothermic peaks characteristic of melting transition and on cooling rate - exothermic peaks of crystallisation. The second heating and cooling rates were characterised by the same thermal behaviour.
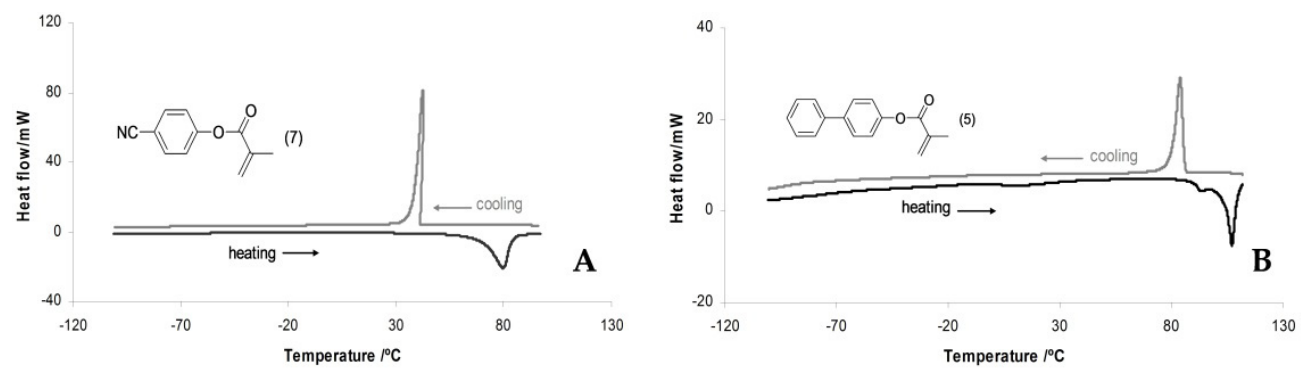

Figure 12. DSC measurement obtained for A) monomer 7 and B) monomer 5 during cycle I at $10^{\circ} \mathrm{C} \mathrm{min}{ }^{-1}$.
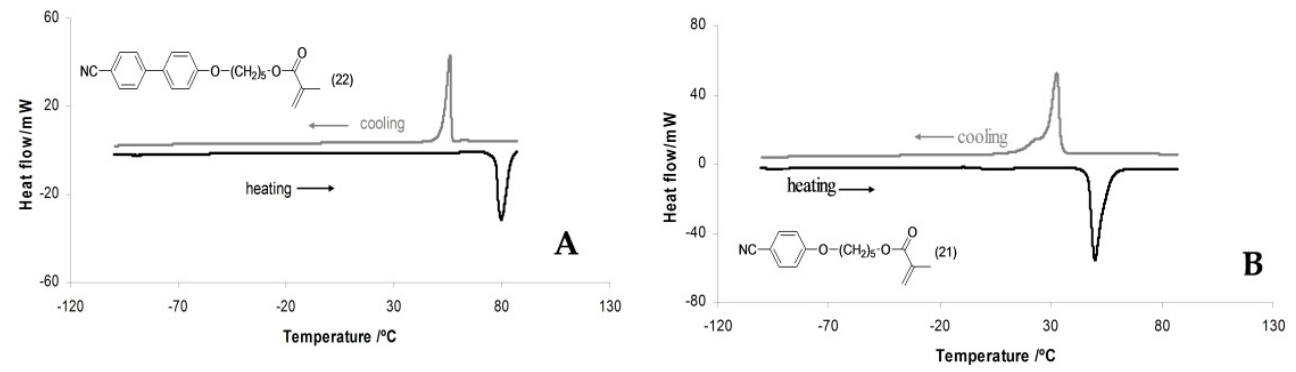

Figure 13. DSC measurement obtained for A) monomer 22 and B) monomer 21 during cycle I at $10^{\circ} \mathrm{C}$ $\min ^{-1}$.

Monomer 20 (figure 14A), despite having the same thermal behaviour as described above, it was not reversible. The thermogram of monomer 20 showed that the crystalline form melted and partially crystallised on cooling. During the first heating rate it exhibited endothermic peak due to melting transition with $\Delta \mathrm{Hm}=57.84 \mathrm{Jg}^{-1}$ and during the cooling - exothermic peak 
due to melt-crystallisation but with $\Delta \mathrm{H}_{\mathrm{cr}}=-18.65 \mathrm{Jg}^{-1}$. During the second heating this crystalline solid formed melted with $\Delta \mathrm{Hm}=14.93 \mathrm{Jg}^{-1}$ and partially crystallised again on cooling, but also with lower value of $\Delta \mathrm{Hcr}=-2.86 \mathrm{Jg}^{-1}$. The difference between the values of enthalpies associated with endothermic and exothermic transitions suggested that part of the material previously melted could have remained in supercooled state, degraded or polymerised, and only a small fraction of the monomer crystallised during cooling run. This possibility was supported by previous studies of DSC between 25 and $200^{\circ} \mathrm{C}$, which indicated that the temperature of $100^{\circ} \mathrm{C}$ seemed to be enough to initiate polymerisation of the monomer.

All these monomers revealed high tendency to organise in crystalline form that melted during the heating run followed by melt-crystallisation during the cooling run. The only thermal event during the heating run was the melting transition that showed that until melting the material was in a crystalline phase.

The insertion of a spacer chain, in monomers 20, 21 and 22 decreased the melting temperatures, compared to the analogue monomers without the spacer chain, which have made the later structures more rigid.
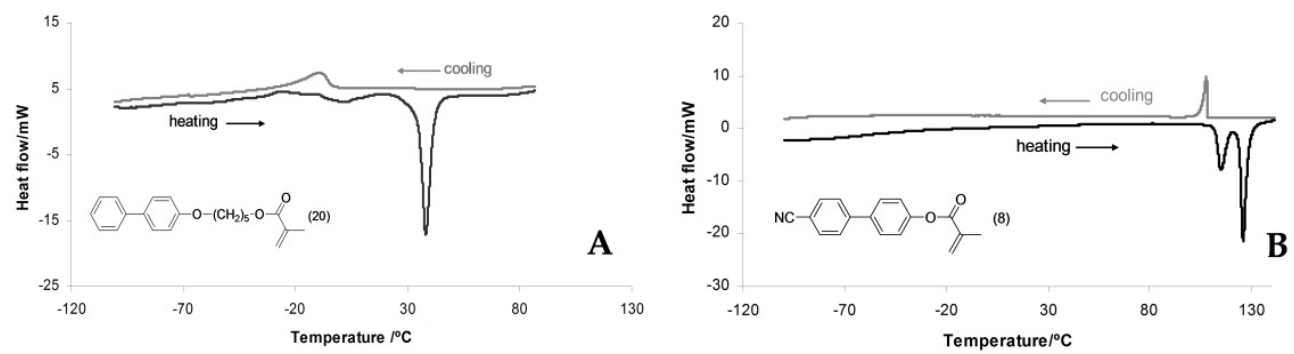

Figure 14. DSC measurement obtained for A) monomer 20 and B) monomer 8 during cycle I at $10^{\circ} \mathrm{C}$ $\min ^{-1}$.

It can be seen in figure 14B that for monomer 8 on the heating run there were two endothermic peaks at 114.95 and $125.90^{\circ} \mathrm{C}$ with enthalpies of 29.09 and $60.40 \mathrm{Jg}^{-1}$, respectively. However on the cooling run only one exothermic peak emerged at $107.72^{\circ} \mathrm{C}$ with enthalpy of $-14.74 \mathrm{Jg}^{-1}$. During the second heating run part of the amorphous material underwent cold crystallisation at $\mathrm{T}_{\mathrm{cc}}=63.61^{\circ} \mathrm{C}$ with an enthalpy of $-10.43 \mathrm{Jg}^{-1}$ followed by two endothermic transitions at 109.60 and $123.95{ }^{\circ} \mathrm{C}$ with 7.48 and $12.13 \mathrm{Jg}^{-1}$, respectively. On the second cooling run no transitions were detected, so it was possible that the liquid have remained in supercooled state or that it had polymerised previously. This last possibility was supported by DSC studies between $25-200^{\circ} \mathrm{C}$. POM studies allowed better understanding of the thermal transitions, especially those involved in the thermal behaviour of monomer 8. Thus, the data from DSC and POM indicated that crystalline material transited to a mesophase state which could be assigned to the first endothermic peak, followed by transition to an isotropic state, assigned to the second endothermic peak. The peak at $114.95^{\circ} \mathrm{C}$ could be assigned to solid to mesophase transition temperature (TsM) and at $125.90^{\circ} \mathrm{C}$ to mesophase to isotropic transition temperature (ТмI). 


\subsection{Polarised optical microscopy characterisation}

The thermal properties of monomers were complemented with polarised optical microscopy (POM) studies. The polarised optical microscope equipped with a hot stage only allows the observation of transitions from 20 to $300^{\circ} \mathrm{C}$ and therefore for the liquid monomers an analysis by POM with the same conditions used in DSC $\left(-130\right.$ to $\left.25^{\circ} \mathrm{C}\right)$ was not possible. Optical observations allowed the determination of not only temperatures for each transition, but also the texture acquired by the sample. Furthermore, polarised optical microscopy can evaluate the possibility of the existence of liquid crystalline phases. An isotropic phase placed between crossed polarisers does not allow polarised light to pass through and what is observed is simply a black uniform image, unlike what is observed for a birefringent phase (optical anisotropy). The values of the thermal proprieties determined by POM are summarised in table 3.

\begin{tabular}{|c|c|c|c|c|c|c|c|c|c|}
\hline \multirow[b]{3}{*}{ Monomer } & \multirow[b]{3}{*}{ Cycle } & \multicolumn{5}{|c|}{ Heating run at $10^{\circ} \mathrm{C}$ min $^{-1}$} & \multicolumn{3}{|c|}{ Cooling run at $10^{\circ} \mathrm{C} \mathrm{min}-1$} \\
\hline & & \multirow{2}{*}{$\begin{array}{l}\begin{array}{l}\text { glass } \\
\text { transition }\end{array} \\
\mathrm{T}_{\mathrm{g}} /{ }^{\circ} \mathrm{C}\end{array}$} & \multicolumn{2}{|c|}{$\begin{array}{l}\text { Cold- } \\
\text { crystallisation }\end{array}$} & \multicolumn{2}{|c|}{ Melting } & \multicolumn{2}{|c|}{$\begin{array}{l}\text { Melt- } \\
\text { crystallisation }\end{array}$} & \multirow{2}{*}{$\begin{array}{l}\begin{array}{l}\text { Glass } \\
\text { transition }\end{array} \\
\mathrm{T}_{\mathrm{g}} /{ }^{\circ} \mathrm{C}\end{array}$} \\
\hline & & & $\mathrm{T}_{\mathrm{cc}} /{ }^{\circ} \mathrm{C}$ & $\begin{array}{l}\Delta \mathrm{H}_{\mathrm{cr}} / \\
\mathrm{Jg}^{-1} \\
\end{array}$ & $\mathrm{~T} \mathrm{~m} /{ }^{\circ} \mathrm{C}$ & $\begin{array}{l}\Delta \mathrm{H}_{\mathrm{m}} / \\
\mathrm{Jg}^{-1} \\
\end{array}$ & $\mathrm{~T}_{\mathrm{c}} /{ }^{\circ} \mathrm{C}$ & $\begin{array}{l}\Delta \mathrm{H}_{\mathrm{cr}} / \\
\mathrm{Jg}^{-1}\end{array}$ & \\
\hline \multirow{2}{*}{19} & $\mathrm{I}$ & -86.01 & -40.19 & -97.45 & -3.62 & 115.52 & - & - & - \\
\hline & II & -86.01 & -39.83 & -96.60 & -3.58 & 114.80 & - & - & - \\
\hline \multirow{2}{*}{1} & I & - & - & - & 18.86 & 108.97 & - & - & - \\
\hline & II & -89.02 & -55.13 & -71.00 & 18.86 & 107.67 & - & - & - \\
\hline \multirow{2}{*}{7} & I & - & - & - & 81.53 & 56.03 & 44.28 & 91.92 & - \\
\hline & II & - & - & - & 79.52 & 76.00 & 38.26 & -90.85 & - \\
\hline \multirow{2}{*}{5} & I & - & - & - & & & 83.99 & -83.45 & - \\
\hline & II & - & - & - & 106.04 & 71.35 & 82.72 & -82.02 & \\
\hline \multirow{2}{*}{8} & I & - & - & - & $\begin{array}{l}114.95 \\
125.90\end{array}$ & $\begin{array}{l}29.09 \\
60.40\end{array}$ & 107.72 & -14.74 & - \\
\hline & II & & 63.61 & -10.43 & $\begin{array}{l}109.60 \\
123.95 \\
\end{array}$ & $\begin{array}{l}7.48 \\
12.13 \\
\end{array}$ & - & - & - \\
\hline \multirow{2}{*}{21} & I & - & - & - & 49.80 & 115.70 & 32.53 & -105.98 & - \\
\hline & II & - & - & - & 49.68 & 111.52 & 31.28 & -91.19 & \\
\hline \multirow{2}{*}{20} & I & - & - & - & 38.19 & 57.84 & -9.24 & -18.65 & - \\
\hline & II & - & - & - & 16.27 & 26.48 & -8.13 & -2.87 & - \\
\hline \multirow{2}{*}{22} & I & - & - & - & 79.77 & 85.21 & 55.90 & -64.55 & - \\
\hline & II & - & - & - & 78.14 & 69.36 & 53.71 & -24.29 & - \\
\hline
\end{tabular}

Table 2. Thermal properties of monomers obtained by DSC during different cooling/heating cycles

The texture for liquid monomers 19 and 1 which may be analysed in the optical microphotographs presented in figure 15, revealed an isotropic phase on heating and the cooling runs between 30 and $100^{\circ} \mathrm{C}$ and no birefringent phase was observed. The spheres that appear in the images are spacers of ITO cell. 
Optical microscopy pictures of monomers 7, 5, 22, 21 and 20 are present in figures 16-20. The analysis of these figures revealed a birefringent texture in the solid state. However, this property was lost with melting transition and the liquid state showed an optic isotropic structure that remained until the crystallisation temperature where again the monomers acquire a birefringent texture.

As mentioned before, in DSC analysis monomer 8 showed a particular thermal behaviour with two endothermic transitions one after the other in the heating run. The results of combined POM and DSC studies allow a better understanding of the type of transitions involved in all the monomers and in particular in monomer 8. The optical microscopy picture presented in figure 21 shows in the heating run that the birefringent solid material first transition to a mesophase at $114^{\circ} \mathrm{C}$ (Tsm). This mesophase was assigned based on the observation of birefringence and fluidity. However this phase with the increase of temperature transited to an isotropic phase at $124^{\circ} \mathrm{C}$ (TMI). During the cooling run, at $102^{\circ} \mathrm{C}$ the isotropic phase crystallised out, so that in the second heating run transit to an isotropic phase at $124^{\circ} \mathrm{C}$. This isotropic phase crystallised at $100^{\circ} \mathrm{C}$ into a birefringent material. From POM studies it was possible to observe the onset of polymerisation at $140{ }^{\circ} \mathrm{C}$ which is in agreement with the DSC analysis.

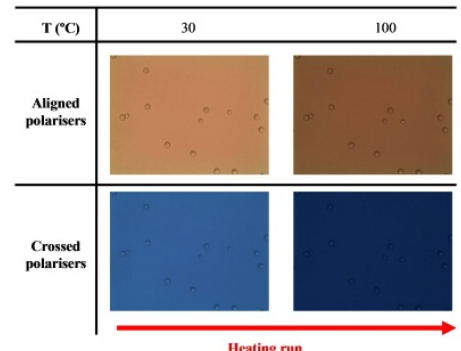

A

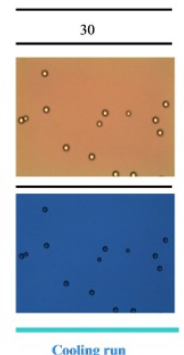

Cooling run (19)

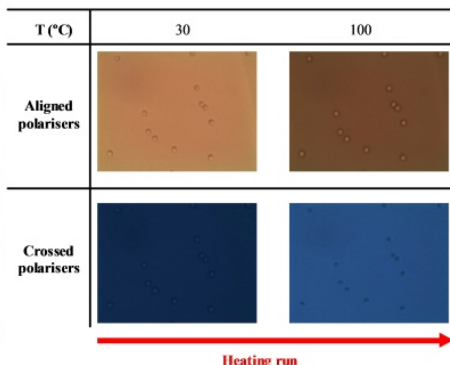

B

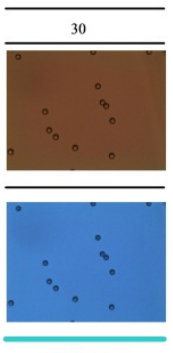

Cooling run

Figure 15. Optical micrographs of A) monomer 19 and B) monomer 1 at specific temperatures during the heating and cooling runs at $10^{\circ} \mathrm{C} \mathrm{min}^{-1}$.

The melting temperature determined by DSC for all the monomers analysed seemed to be corroborated by the melting temperature determined by capillarity. However, the transition temperatures determined by POM showed small differences. Although the programme for the heating and the cooling runs was the same $\left(10^{\circ} \mathrm{Cmin}^{-1}\right)$ it was difficult to keep exactly the same ramp throughout the POM analysis. During POM measurements the runs of heating and cooling were stopped momentarily to take optical micrographs. 

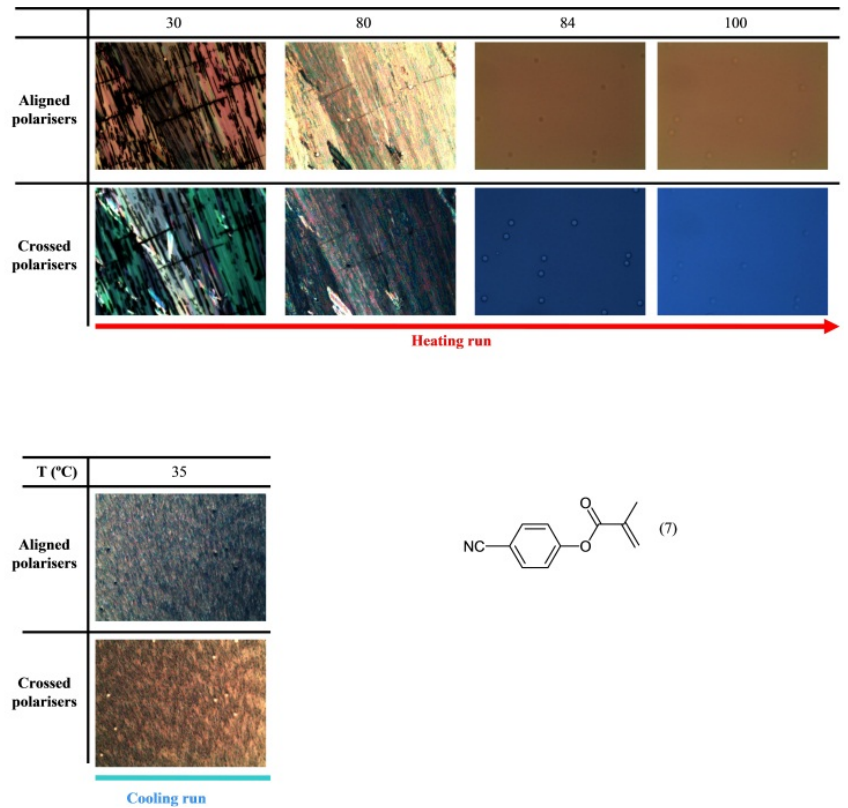

Figure 16. Optical micrographs of monomer 7 at specific temperature during the heating and cooling run at $10^{\circ} \mathrm{C} \mathrm{min}^{-1}$.
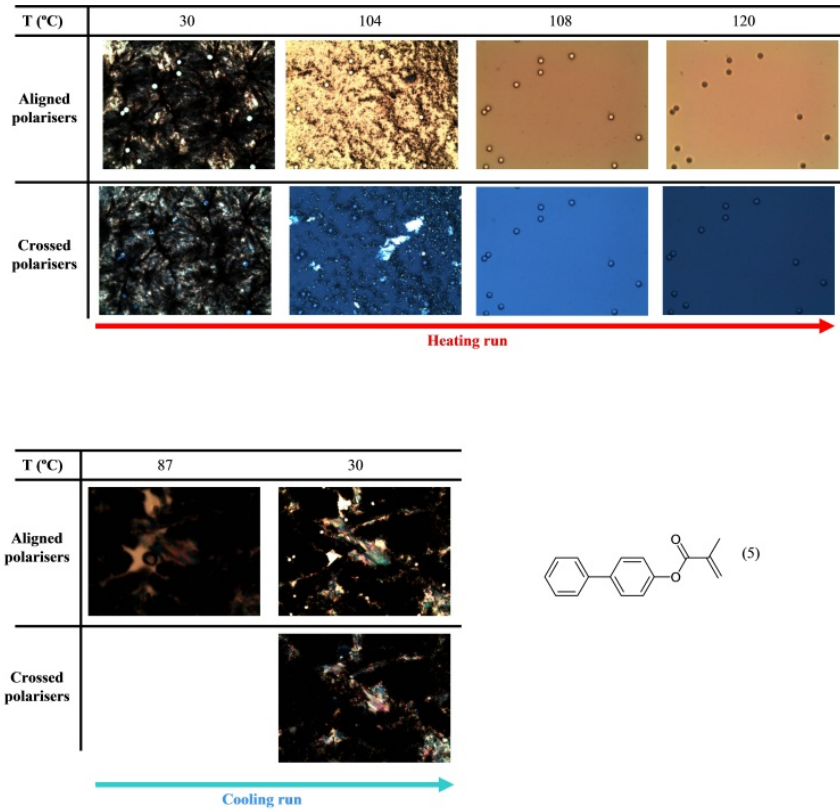

Figure 17. Optical micrographs of monomer 5 at specific temperatures during the heating and cooling runs at $10^{\circ} \mathrm{C} \mathrm{min}^{-1}$. 

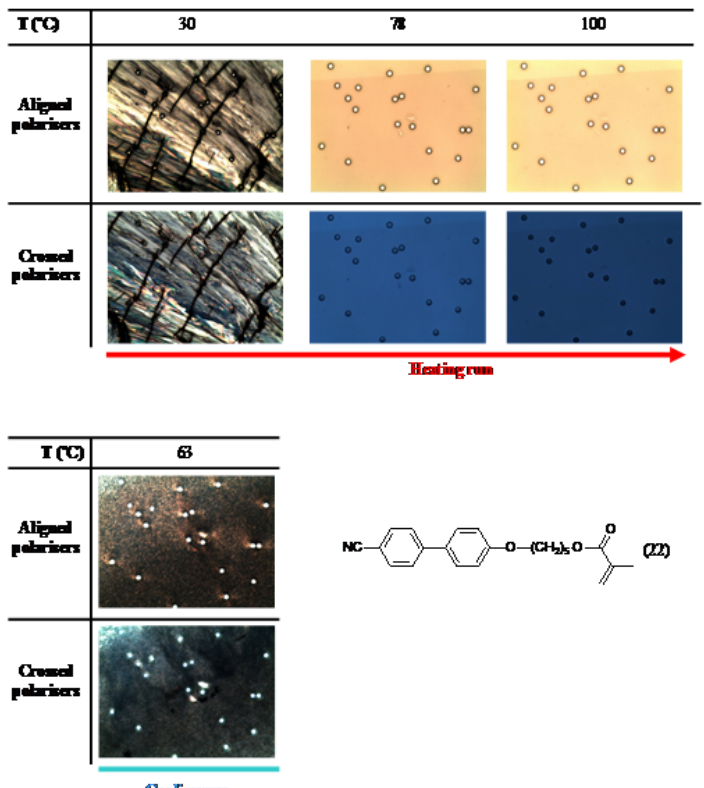

Figure 18. Optical micrographs of monomer 22 at specific temperatures during the heating and cooling runs at $10^{\circ} \mathrm{C} \mathrm{min}^{-1}$.
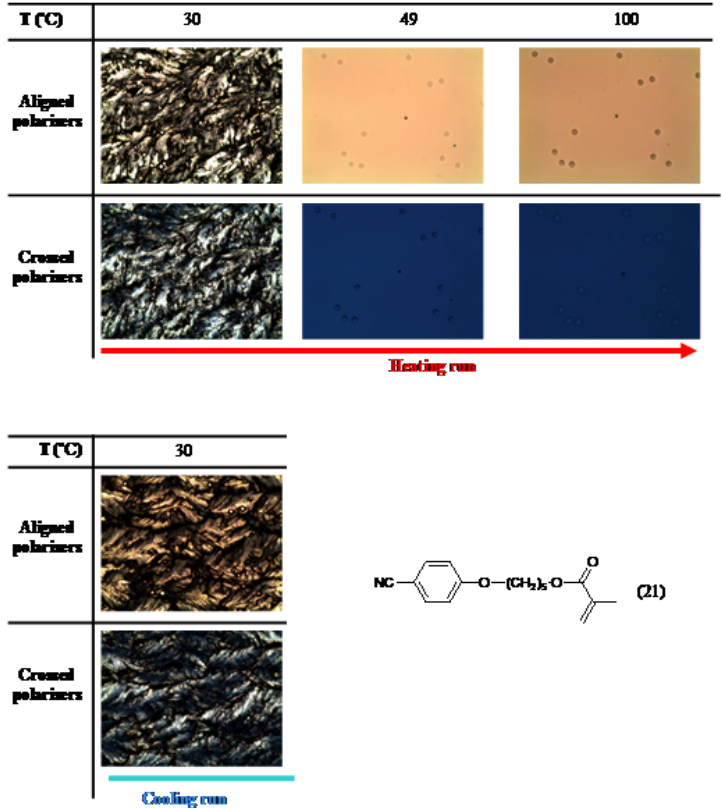

Figure 19. Optical micrographs of monomer 21 at specific temperatures during the heating and cooling run at $10^{\circ} \mathrm{C} \mathrm{min}^{-1}$. 

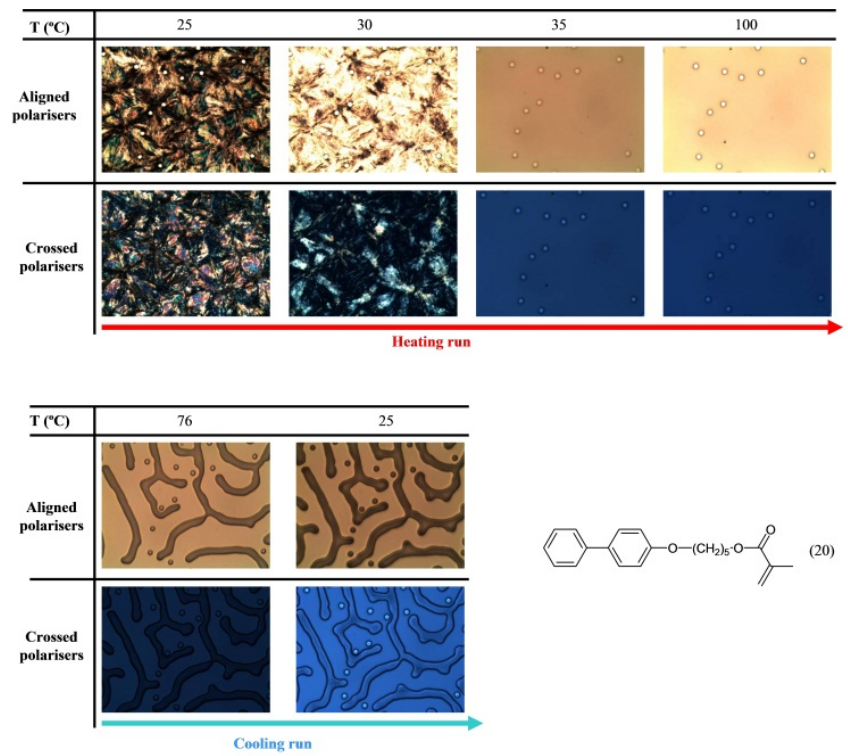

Figure 20. Optical micrographs of monomer 20 at specific temperatures during the heating and cooling runs at $10^{\circ} \mathrm{C} \mathrm{min}^{-1}$.

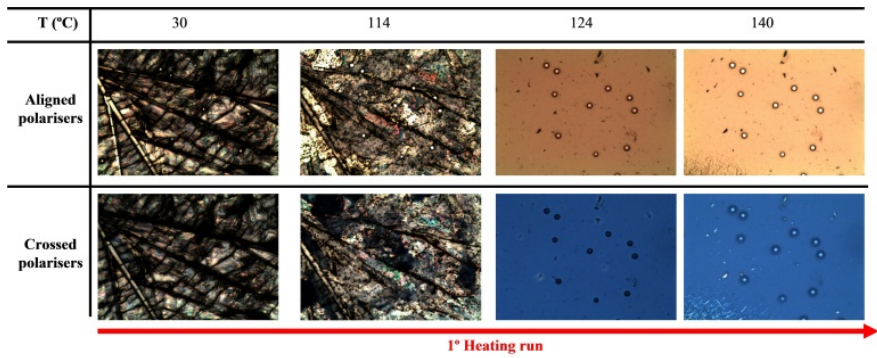

I" Heating run

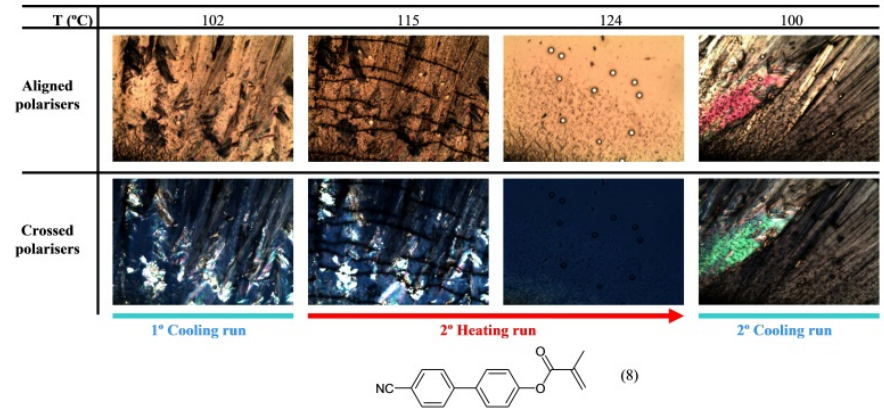

Figure 21. Optical micrographs of monomer 8 at specific temperatures during the first and second heating at $10^{\circ} \mathrm{C} \mathrm{min}^{-1}$. 


\begin{tabular}{|c|c|c|c|c|c|}
\hline \multirow[b]{3}{*}{ Monomer } & \multirow[b]{3}{*}{ Initial optical property } & \multicolumn{2}{|c|}{ Heating run at $10^{\circ} \mathrm{C}$ min $^{-1}$} & \multicolumn{2}{|c|}{ Cooling run at $10^{\circ} \mathrm{C} \mathrm{min}^{-1}$} \\
\hline & & \multicolumn{2}{|r|}{ Melting } & \multicolumn{2}{|c|}{ Melt-crystallisation } \\
\hline & & $\mathrm{T} /{ }^{\circ} \mathrm{C}$ & Optical property & $\mathrm{T}_{\mathrm{c}} /{ }^{\circ} \mathrm{C}$ & Optical property \\
\hline 19 & Isotropic & - & - & - & - \\
\hline 1 & Isotropic & - & - & - & - \\
\hline 7 & Birefringent & $84\left(\mathrm{~T}_{\mathrm{m}}\right)$ & Isotropic & 35 & Birefringent \\
\hline 5 & Birefringent & $108\left(\mathrm{~T}_{\mathrm{m}}\right)$ & Isotropic & 87 & Birefringent \\
\hline 22 & Birefringent & $78\left(\mathrm{~T}_{\mathrm{m}}\right)$ & Isotropic & 63 & Birefringent \\
\hline 21 & Birefringent & $49\left(\mathrm{~T}_{\mathrm{m}}\right)$ & Isotropic & 30 & Birefringent \\
\hline 20 & Birefringent & $35(\mathrm{Tm})$ & Isotropic & - & - \\
\hline 8 & Birefringent & $\begin{array}{l}114 \text { (Tsм) } \\
124 \text { (TMI) }\end{array}$ & $\begin{array}{l}\text { Birefringent } \\
\text { Isotropic }\end{array}$ & 102 & Birefringent \\
\hline
\end{tabular}

Table 3. Thermal properties of monomers obtained by POM during heating/cooling runs.

\section{Structural and electro-optical characterisation}

\subsection{Molecular weights and polymer structures}

The molecular weight of the polymer matrix plays an important role in the morphologies of the matrix and therefore in the liquid crystal domain size and shape. If the polymer chain increases with an increase in molecular weight leading to a higher network density, the size of liquid crystal domains should decrease. This promotes the interaction between polymer and liquid crystal molecules; the opposite is valid for smaller chains. As previously mentioned, the size and the shapes of liquid crystal domains are correlated with the anchoring strength on the interface between the liquid crystal molecules and polymer molecules. The anchoring strength determines the electric field needed to achieve the transparent state in the PDLC. Generally, the strength of the field needed is inversely proportional to the liquid crystal domain size. A number of factors influence the electrooptical response of PDLCs and the investigation of these parameters allows control of the performance of these devices. So, it is important to understand and establish the effect of the molecular structure of the polymerisable monomers on the molecular weight of the polymer and the effect of molecular weight on the morphology and electro-optical properties.

\subsection{Characterisation of molecular weights}

Gel permeation chromatography (GPC) is a liquid chromatography technique that separates molecules according to sizes and not according to chemical affinities toward the porous substrate $^{39}$.Large polymer molecules with higher molecular weights can move into pores but since there are only few large pores available to them, they reside, on average, less time in pores than smaller molecules. Therefore, larger molecules are eluted first. On the other hand, smaller polymer molecules with lower molecular weights can fit into the small pores and penetrate into a larger number of pores. So, the elution time increases with decreasing molecular size ${ }^{40}$. This correlation between elution time and molecular weight was observed for the polymers analysed. The values of average molecular weights $\left(M_{n}\right.$ and $\left.M_{w}\right)$ and 
polydispersity index (PDI) for mixture of monomer/glycidyl methacrylate (50/50 w/w) after thermal and photochemical polymerisations are summarised in Tables 4 and 5, respectively. It was possible to observe differences between polymer matrixes prepared by thermal polymerisation and by photochemical polymerisation. For thermal polymerisation, the polymers had a number average molecular weight, $\mathrm{Mn}$, around $\mathrm{e}^{8}$ or $\mathrm{e}^{12}$, and for photochemical polymerisation polydispersions were higher and $\mathrm{Mn}$ was around $\mathrm{e}^{12}$. Generally, the polymers with lower molecular weight possessed lower polydispersion, indicating that there were chains with more uniform lengths (sizes), but no correlation was observed with the molecular structure of the respective monomers.

\subsection{Microstructure of the polymer matrix}

The microscopic images of the microstructure of the polymeric matrix were evaluated by scanning electronic microscopy (SEM). Some microscopic images can be assigned to the Swiss cheese (figure 22A) or polymer ball (figure 22B) types of morphology, but for some samples these morphologies were not uniform across the sample. For other samples it was not possible to identify any morphology. These results can suggest that the chemical affinity of polymerisable monomers with liquid crystal molecules due to their similarities in chemical structure produced smaller phase separation and therefore the E7 liquid crystal molecules

\begin{tabular}{ccccc}
\hline $\begin{array}{c}\text { Monomers used in } \\
\text { co-polymerisation }\end{array}$ & PDI & Peak/min & $\ln \left(\mathbf{M}_{\mathbf{w}} / \mathbf{g m o l}^{-1}\right)$ & $\ln \left(\mathbf{M}_{\mathbf{n}} / \mathbf{g m o l}^{-1}\right)$ \\
\hline $\mathbf{8}$ & 1.91 & 13.86 & 12.80 & 12.15 \\
$\mathbf{2 2}$ & 1.40 & 14.97 & 12.51 & 12.16 \\
$\mathbf{1 9}$ & 1.44 & 13.57 & 13.05 & 12.69 \\
$\mathbf{5}$ & 1.04 & 20.51 & 8.13 & 8.09 \\
$\mathbf{7}$ & 1.04 & 20.81 & 8.02 & 7.99 \\
$\mathbf{2 1}$ & 1.04 & 20.47 & 8.16 & 8.12 \\
$\mathbf{2 0}$ & 1.05 & 20.14 & 8.22 & 8.17 \\
\hline
\end{tabular}

Table 4. Values of average molecular weights $\left(\mathrm{M}_{\mathrm{n}}\right.$ and $\mathrm{M}_{\mathrm{w}}$ ) and polydispersity index (PDI) for polymers prepared with a mixture of monomer/glycidyl methacrylate $(50 / 50 \mathrm{w} / \mathrm{w})$ by thermal polymerisation.

\begin{tabular}{ccccc}
\hline $\begin{array}{c}\text { Monomers used in } \\
\text { co-polymerisation }\end{array}$ & PDI & Peak/min & ln $\left(\mathbf{M}_{\mathbf{w}} / \mathbf{g m o l}^{-1}\right)$ & $\ln \left(\mathbf{M n}_{\mathbf{n}} / \mathbf{g m o l}^{-1}\right)$ \\
\hline $\mathbf{8}$ & 1.51 & 14.28 & 12.80 & 12.39 \\
$\mathbf{2 2}$ & 1.47 & 14.68 & 12.36 & 11.98 \\
$\mathbf{1 9}$ & 1.35 & 15.06 & 12.04 & 11.74 \\
$\mathbf{5}$ & 1.24 & 15.78 & 11.67 & 11.45 \\
$\mathbf{7}$ & 1.08 & 14.37 & 12.30 & 12.23 \\
$\mathbf{2 1}$ & 1.38 & 15.63 & 11.72 & 11.39 \\
$\mathbf{2 0}$ & 1.36 & 22.36 & 6.99 & 6.68 \\
\hline
\end{tabular}

Table 5. Values of average molecular weights $\left(\mathrm{M}_{\mathrm{n}}\right.$ and $\mathrm{M}_{\mathrm{w}}$ ) and polydispersity index (PD) for polymers prepared with a mixture of monomer/glycidyl methacrylate $(50 / 50 \mathrm{w} / \mathrm{w})$ by photochemical polymerisation. 

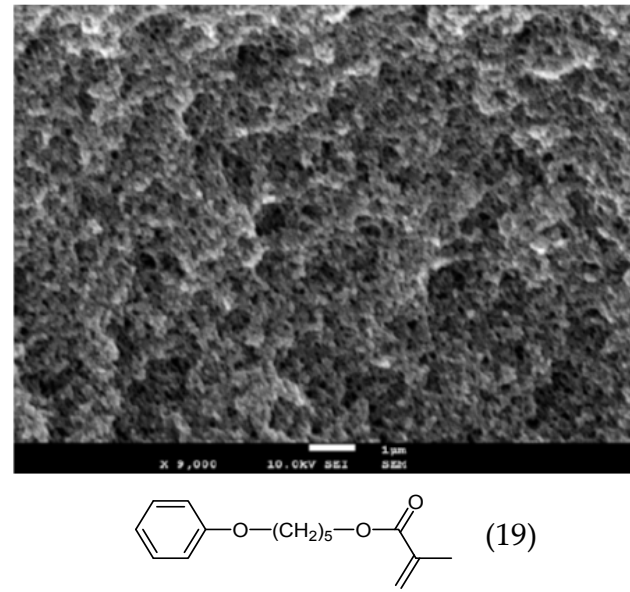

(19)

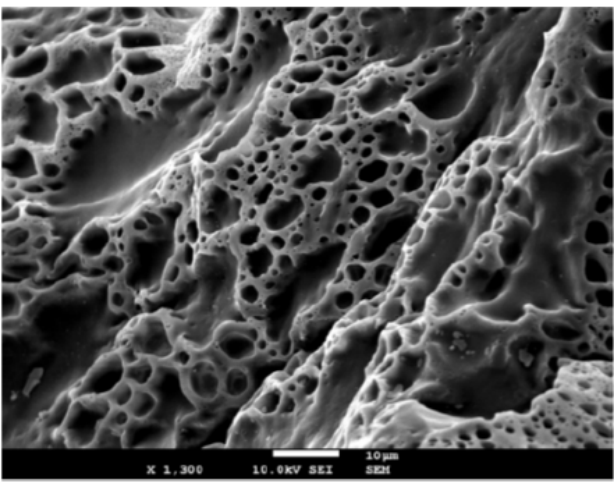

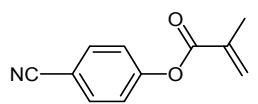

Figure 22. Examples of SEM micrographs for the microstructure of the polymer matrix prepared by thermal polymerisation of A) monomer 19 and B) monomer 7 .

would be highly embedded in the matrix. It was also possible to observe that there could not be established a correlation between the molecular structure of the polymerisable monomers and polymerisation conditions. Although the samples for analysis by GPC and SEM were not prepared under the same conditions, it was not possible to establish a correlation between the molecular weight of polymers and the microstructure of the polymer matrix.

\subsection{Electro-optical characterisation}

The PDLCs prepared with the monomers synthesised showed poor electro-optical response (figure 23). In most of the studies the PDLC cells showed good opacity after polymerisation with transmittance of the initial opaque state TOFF $0 \%$. However, the electro-optical study did not reveal significant difference on the transmission of the sample with the application of electric field up to $400 \mathrm{~V}\left(20 \mathrm{~V} \mu^{-1}\right)$, the maximum transmittance, TMAX, being less than $4 \%$. The reason for this non-ideal behaviour is unclear, however, it was possible to suggest explications.

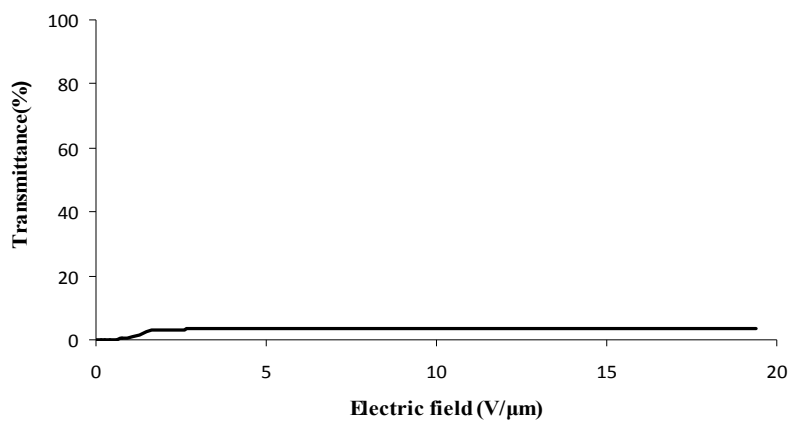

Figure 23. General electro-optical response for PDLC films prepared by the PIPS method with the monomers synthesised + E7 in a ratio of 30/70 (w/w). 
As mentioned before, the electro-optical properties of PDLC films depend on numerous parameters, namely, the structure and the molecular weight of the polymeric matrix (size and shape of the liquid crystal domains). These factors control the dynamics between alignment and random distribution when the electric field is applied and after removal of the electric field, respectively. These dynamics are very much dependent on anchoring force. This force is related to the interactions between the liquid crystal molecules and the polymeric matrix at the interface of LC domains and polymer matrix. The electro-optical results for PDLC films studied in this work suggested that higher molecular affinity between the polymeric matrix and the liquid crystal could increase the anchoring effect.

The similar molecular structure between the molecules of monomer and the LC could have led to higher affinity between molecules of polymer and molecules of liquid crystal in the interfaces matrix-LC domains. In this way, the electric field applied could not overcome the interactions at the interface and the PDLC remained in an opaque state. This was due to the fact that if the liquid crystal molecules do not align themselves along the electric field, the PDLC films appear opaque. The higher affinity between molecular structure of polymer matrix and LC molecules caused an increase in anchoring strength, i.e. it hindered the alignment of the liquid crystal molecules and could be the cause of the low electro-optical response of PDLC films.

In conclusion, the chemical affinity between the polymerisable monomers and the liquid crystal molecules was able to provide better affinity between the two which created more homogeneous mixture with consequent phase separation, in which the liquid crystal was uniformly dispersed in the polymer matrix. However, this affinity could be high enough to increase the anchoring effect not allowing a good electro-optical response.

\section{Conclusions}

A series of new monomers with structurally diverse functionalisation was successfully synthesised under microwave irradiation. These results were compared with those obtained following classical methods. The comparison of these methodologies clearly indicated the considerable reduction in time and amount of solvent used in the reactions performed under microwave irradiation. Therefore, two important advantages, reduction in time and solvents, obtained by the use of microwave irradiation were demonstrated. Beyond that, the majority of monomers were synthesised in one step and in some cases in two steps, which provided simple and effective methods of synthesis. The GPC analysis of co-polymers (monomers synthesised and glicidyl methacrylate) revealed that it was not possible to establish a correlation between the molecular structure of the polymerisable monomers and the molecular weight of polymers. The microstructure of the polymer matrix was evaluated by SEM. From these studies, it was also not possible to establish a correlation between the molecular structure and molecular weight of the respective monomers. Nevertheless, the absence of a typical morphology on most microscopic images seemed to indicate that the liquid crystal remained highly impregnated in the polymer matrix and thus, their microdomains could not be visualised. The phase transformations of the monomers were investigated by DSC and complemented by POM. In general, the thermal behaviour seems to 
be that of a reversible system and the monomers show a high tendency to melting followed by a melt-crystallisation. The spacer chain in the molecular structure of the monomers decreases the melting temperature in comparison with the respective monomers without this chain. The POM analyses confirmed the transition determined by DSC and allowed an observation of the texture acquired by the sample. The analysis of solid monomers showed a birefringent texture in the solid state that where lost in the melting transition where an isotropic phase is acquired. However, monomer 8 revealed a different thermal behaviour with a mesophase between $114-124^{\circ} \mathrm{C}$. On the other hand, the liquid monomers showed isotropic properties in all temperature ranges.

The electro-optical responses of all PDLCs prepared by the PIPS method with the composites of monomers synthesised-E7 exhibit a lower transmittance upon the application of an electric field. This behaviour can be interpreted as the result of a higher anchoring effect. Thus, even the application of a higher electric field could not orient the E7 molecules along the direction of the electric field and they scattered strongly the incident light. The similarity in molecular structure between the molecules of polymerisable monomers and LC should allow a good chemical affinity between them and a better homogenisation of the mixture and a uniform phase separation can be achieved but it should not be too high to avoid a higher anchoring effect which resulted in a low electro-optical response of the PDLCs.

\section{Author details}

Ana Isabel Mouquinho, Krasimira Petrova, Maria Teresa Barros and João Sotomayor REQUIMTE, CQFB, Departamento de Química, Faculdade de Ciências e Tecnologia, Universidade Nova de Lisboa, Caparica, Portugal

\section{Acknowledgement}

This work was supported by Fundação para a Ciência e Tecnologia through Project PTDC/CTM/69145/2006.

\section{References}

[1] Drazaic, P. S., Liquid Crystal Dispersions World Scientific Publishing: Singapore, 1995.

[2] Benkhaled, L.; Coqueret, X.; Traisnel, A.; Maschke, U.; Mechernene, L.; Benmouna, M., A Comparative Study of UV and EB-Cured PDLC Films via Electro-Optical Properties. Mol. Cryst. Liq. Cryst. 2004, 412, 477/[2087]-483/[2093].

[3] Park, S.; Hong, W. J., Polymer dispersed liquid crystal film for variable-transparency glazing. Thin Solid Films 2009, 517, 3183-3186.

[4] Devdatt, L. K.; Nikolaos, A. P., Method of Determination of Initiator Efficiency: Application to UV Polymerizations Using 2,2-Dimethoxy-2-phenylacetophenone. Macromolecules 1994, 27, 733-738.

[5] Ates, S.; Aydogan, B.; Torun, L.; Yagci, Y., Synthesis and characterization of triptycene type cross-linker and its use in photoinduced curing applications. Polymer 2010, 51, 825-831. 
[6] Bedjaoui, L.; Gogibus, N.; Ewen, B.; Pakula, T.; Coqueret, X.; Benmouna, M.; Maschke, U., Preferential Solvation of the eutectic mixture of liquid crystal E7 in a polysiloxane. Polymer 2004, 45, 6555-6560.

[7] Brás, A., R., E.; Henriques, S.; Casimiro, T.; Aguiar-Ricardo, A.; Sotomayor, J.; Caldeira, J.; Santos, C.; Dionísio, M., Characterization of a Nematic Mixture by Reversed-Phase HPLC and UV Spectroscopy: Application to Phase Behavior Studies in Liquid Crystal$\mathrm{CO}_{2}$ Systems. Liq. Cryst. 2007, 34, 591-597.

[8] Li, W.; Cao, Y.; Kashima, M.; Kong, L.; Yang, H., Control of the Microstructure of Polymer Network and Effects of the Structures of Polymerizable Monomers On the Electro-optical properties of UV- Cured Polymer Dispersed Liquid Crystal Films. J. Polym. Sci., Part B: Polym. Phys. 2008, 46, 1369-1375.

[9] Vaz, N. A.; Montgomery, G. P., Refractive indices of polymer-dispersed liquid crystal film materials: Epoxy based systems. J. Appl. Phys. 1987, 62, 3161-3172.

[10] Bulgakova, S. A.; Mashin, A. I.; Kazantseva, I. A.; Kashtanov, D. E.; Jones, M. M.; Tsepkov, G. S.; Korobkov, A. V.; Nezhdanov, A. V., Influence of the Composition of the Polymer Matrix on the Electrooptical Properties of Films with a Dispersed Liquid Crystal. Russ. J. Appl. Chem. 2008, 81 1446-1451.

[11] K.; Blaaderen, A., V.; Wiltzius, P., Morphology and electro-optical properties of polymer-dispersed liquid crystal films Am. Phys. Soc. 1997, 55, 1646-1654.

[12] Han, W. J., Morphological Studies of Polymer Dispersed Liquid Crystal Materials. Korean J.Phys.Soc. 2006, 49, 563-568.

[13] Nomura, H.; Suzuki, S.; Atarashi, Y., Electrooptical Properties of Polymer Films Containing Nematic Liquid Crystal Microdroplets. Jpn. J. Appl. Phys. 1990, 29, 522-528.

[14] Yokoyama, H., Surface Anchoring of Nematic Liquid Crystals. Mol. Cryst. liq. Cryst. 1988, 165, 265-316.

[15] Andy, F. Y. G.; Tsung, C. K.; Mo, H. L., Polymer Dispersed Liquid crystal Films with memory characteristics. J. Appl.Phys. 1992, 31, 3366-3369.

[16] Rumiko, Y.; Susumu, S., Highly transparent memory states by phase transition with a field in polymer dispersed liquid crystal films. J. Appl. Phys. 1992, 31, 254-256.

[17] Yan, B.; He, J.; Bao, R.; Bai, X.; Wang, S.; Zeng, Y.; Wang, Y., Modification of electrooptical properties of polymer dispersed liquid crystal films by iniferter polymerization. Eur. Polym. J. 2008, 44, 952-958.

[18] Wonsool, A.; Ha, K., Temperature effects on LC Droplets Formation of PDLC films with thermoplastic Matrix. Korea Polym. J. 1999, 7, 130-135.

[19] He, J.; Bin, Y.; Wang, X.; Yu, B.; Wang, Y., A novel Polymer dispersed Liquid Crystal film prepared by reversible addition fragmentation chain transfer polymerization. Eur. Polym. J. 2007, 43, 4037-4042.

[20] Ahmad, F.; Jamil, M.; Jeon, Y. J.; Woo, L. J.; Jung, J. E.; Jang, J. E.; Lee, G. H.; Park, J., Comparative study on the electrooptical properties of polymer-dispersed liquid crystal films with different mixtures of monomers and liquid crystals. J. Appl.Polym. Sci. 2011, $121,1424-1430$.

[21] Manni, A.; Gobbi, L.; Simoni, F., Novel PDLC Films Based On a Photoactive Polymeric Binder. Mol. Cryst. Liq. Cryst. 2003, 398, 281-291.

[22] Orzeszko, B.; Ksyta, M. D.; Orzeszko, A., An Efficient, Facile, and Fast Synthesis of 4alkoxy-4'-hydroxybiphenyls. Synth. Commun. 2002, 32, 3425-3429. 
[23] Barros, M. T.; Mouquinho, A.; Petrova, K.; Saavedra, M.; Sotomayor, J., Fast synthesis employing a microwave assisted neat protocol of new monomers potentially useful for the preparation of PDLC films. Cent. Eur. J. Chem 2011, 9, 557-566.

[24] Hayes, B. L., Microwave Synthesis: Chemistry at the Speed of Light CEM Publishing: Matthews, NC, 2002.

[25] http://www.sigmaaldrich.com/ (December,2011).

[26] Mouquinho, A.; Saavedra, M.; Maiau, A.; Petrova, K.; Barros, M. T.; Figueirinhas, J. L.; Sotomayor, J., Films Based on New Methacrylate Monomers: Synthesis, Characterisation and Electro-optical properties. Mol. Cryst. Liq. Cryst. 2011, 542, 132/[654]-140[662].

[27] Reddy, G. J.; Naidu, S. V.; Reddy, A. V., Synthesis and Characterization of Poly(Nphenyl methacrylamide-co-methyl methacrylate) and Reactivity Ratios Determination. J. Appl. Polym. Sci. 2003, 90, 2179.

[28] Casadei, M. A.; Cesa, S.; Inesi, A., Electrochemical Studies on Haloamides. Part XII. Electrosynthesis of Oxazolidine-2,4-diones. Tetrahedron 1995, 51, (20), 5891-5900.

[29] Vijayanand, P. S.; Kato, S.; Satokawa, S.; Kojima, T., Copolymerization of 4-cyanophenyl methacrylate with methyl methacrylate: Synthesis, characterization and determination of monomer reactivity ratios. Polym. Bull 2007, 59, 469-480.

[30] Chênevert, R.; Pelchat, N.; Morin, P., Lipase-mediated enantioselective acylation of alcohols with functionalized vinyl esters: acyl donor tolerance and applications. Tetrahedron: Asymmetry 2009, 20, 1191-1196.

[31] Lal, J.; Green, R., The Preparation of Some Esters of Methacrylic Acid. J. Org. Chem 1955, 20, 1030-1033.

[32] Pinazzi, C; Comptes Rendus des Seances de l'Academie des Sciences. Serie C: Sciences Chimiques 1972, 274, (44).

[33] Braun, J. V.; Steindorff, A., Ueber einige Verbindungen der Pentamethylenreihe. Chem. Berichte (In German) 1905, 38, 956-966.

[34] Slugovc, C.; Demel, S.; Riegler, S.; Hobisch, J.; Stelzer, F., Influence of functional groups on ring opening metathesis polymerisation and polymer properties. J. Mol. Cat. A: Chem. 2004, 213, 107-113.

[35] Berg, S.; Newbery, G., The Search for Chemotherapeutic Amidines. Part X . Substituted 4 : 4'-Diamidino-aw-diphenoxyalkanes and -diphenyl Ethers. J. Chem. Soc. 1949, 642-645.

[36] Yelamaggad, C. V.; Tamilenthi, V. P., Synthesis and thermal properties of liquid crystal trimers comprising cyanobiphenyl and salicylaldimine anisometric segments. Tetrahedron 2009, 65, 6403-6409.

[37] Dneprovskii, A. S.; Tuchkin, A. I., Radical-Anion Nucleophilic Substitution in pBromobenzyl Methyl and p-Bromobenzyl Phenyl Ethers. Competing Fragmentations of Radical Anions. Russ. J. Org. Chem. 1997, 33, 1601-1605.

[38] Ikeuchi, Y.; Taguchi, T.; Hanzawa, Y., Zirconocene-Mediated and/or Catalyzed Unprecedented Coupling Reactions of Alkoxymethyl-Substituted Styrene Derivatives. J. Org. Chem 2005, 11, 4354-4359.

[39] Elias, H.-G., An Introduction to Polymer Science. Wiley-VCH: New York, 1997.

[40] Braun, D.; Cherdron, H.; Rehahn, M.; Ritter, H.; Voit, B., Polymer Synthesis:Theory and practice. 4 ed.; Springer: 2005. 